\title{
Ignoble Fate and Noble Sentiment: On Yan Geling's Feminine Mentality and Her Immortal Fusang
}

\author{
Ju Zhang \\ School of Foreign Languages, Inner Mongolia University for the Nationalities \\ Huolinhe Street, Tongliao City, Inner Mongolia, P. R. China \\ Tel: 86-475-8251117 E-mail: zhangjunm2005@126.com; \\ Suyang Zhang \\ School of Foreign Languages, Inner Mongolia University for the Nationalities \\ Huolinhe Street, Tongliao City, Inner Mongolia, P. R. China \\ Tel: 86-475-8251117Ｅ-mail: zhangjunm2005@126.com
}

Received: April 11, $2011 \quad$ Accepted: April 25, 2011 doi:10.5539/ells.v1n1p14

\begin{abstract}
It is Yan Geling's invariable literary thoughts and feelings that express the real deep affections and experiences of women. As a Chinese American writer, she has invented one Chinese story after another. All her stories are unique, intricate and imbued with deep affectations. In Fusang, Yan Geling revealed the hard, bloody and tragic history of the Chinese immigrants. Her narration is a new annotation of the ancient Chinese femininity, gender relationship and cross-cultural communication. In the novel, the author, basing on cross-cultural communication and combining her personal life experiences with the story, showed deep concern for the survival conditions of the traditional oriental females so as to arouse readers' rational thought and emotional resonance. Through the vivid feminine imagery living at the bottom of the social ladder, Yan opened the window for readers to spy on feminine primitive potency and explore into the secret buried deep in human nature.
\end{abstract}

Keywords: Fusang, Feminine consciousness, Salvation of humanity, Maternal tolerance, Ode to greatness

\section{Literature Review}

In the 1970s, some Chinese American writers, as a new emerging force, began to stand out in North American Literature. Ever since then, the force has been branching out and developing and has reached to a pinnacle in the world of literary creation and criticism just in the past forty years. Influenced by the American Democratic Movements, the Chinese immigrants were gradually awakened in their national awareness and began to take up writing in order to reflect on national identity, to narrate the cultural dilemma of a marginal population, and to improve the Chinese imagery in an attempt to obtain the understanding and acceptance of mainstream society. Impelled by the new form of creative thinking, a number of talented writers and leading figures have come to the fore - such as, Chin Frank, Maxine Hong Kinston, Amy Tan, Yan Geling, Gish Jen, Henry David Hwang and some others. And their literary achievements have drawn more and more attention in the field of dominant culture and their influence has extensively spread throughout the world. These writers have not only deeply attracted many American readers for their influential works but also won common acceptance and many literary awards in the world.

Yan Geling is one of the most influential overseas Chinese writers in America. Arguing from her own female experiences, Ms. Yan has constructed a female world with rich connotations in her novels by constructing a unique form of female dialogue. She has created a series of overseas Chinese characters to make known the cognition, understanding and reflections of the overseas Chinese and their native colony. As a female writer, Yan has adhered to a pure stance of female writing, always taking a feminist perspective through her unique narrative style and humanistic sentiments.

Fusang, or The Lost Daughter of Happiness, a novel by Yan Geling, has become the major concern in the circle of literature since its publication in 1996. This novel lays bare the life of the new Chinese immigrants and also deeply explores the meaning of legends, experiences, perplexities and spiritual journeys.

But nearly no one has ever been sincerely convinced that there was once such a real female as Fusang. Her extraordinary life experiences may be purely fabricated. However, because of Fusang, tribulation and perfect virtue 
have now become many scholars' themes in their research, and though this research is able to show more concern for feminine visualization. Most researchers, proceeding from Feminism and Post-Colonialism, often dissect such problems as feminine consciousness, self identity, traditional virtue, self-sacrifice and great love that are revealed in such novels. However, as a controversial prostitute struggling in the underworld of American society, Fusang, an ignoble streetwalker, has seldom been found to possess unimaginable greatness in filth and loftiness in adversity. Limitation is to be pointed out to former fruits of research on Fusang. In this paper, a research of Fusang will be carried out in a fairly new angle.

\section{Yan Geling's Feminine Mentality in Her Narration}

Yan Geling was born in an intellectual family. Both her grandfather and father were writers and her mother an actress. Under the influence of these loved ones, Yan has a deep love for reading and began writing when she was young. She has had rich life experiences and gained a keen perception of human race. As a woman herself, she may know women better. Maybe just for this reason, she shows more concern for women in nearly all her literary works, especially for Chinese women of traditional type and of low social class. In her creative writing, she has created numerous unchangeable female images that impress upon readers their vulnerability. These images belong to a kind-hearted, virtuous and caring colony that remained aloof of all struggles. They always kept themselves pure and simple in a dirty and evil society where the weak fell prey to the strong, but shimmered for ever with the splendor of humanity as well as realism. They endlessly suffered from miseries and mortifications but never were there any obvious changes taking place in their kind and pure nature. They continuously resigned themselves to tribulation, believing in the philosophy of forgiveness, and often telling redeeming stories of human nature.

Yan Geling's female narrative feelings may derive from her own gender, family background and personal life experiences. It is no doubt that her parents' divorce and her own divorce impacted her so much. In her single life she lived to some extent through a wandering, eventful and painful life. So after her new marriage, Yan felt quite moved to tell to a reporter in an interview, "Without a marriage, I can not imagine what a life I shall live. Besides soulful comfort, my other half always gives me so much complementation, correction and makes me away from absolute ego and bigotry. Any kind person will keep improving himself in the marriage in order to avoid going one's own way doggedly on condition that he or she cares the opposite very much. My years of married life have made me know a lot."

Yan Geling went to study in America for a master's degree in 1988 and settled down after graduation. The Western concept of gender exerted a gradual, uplifting influence on her. And her gender narrative feelings were further aroused by the bitter experiences of the overseas Chinese women, especially more traditional women. In Yan's life time, she was once entangled in taking care of the old and young and in order to maintain her livelihood, worked as waitress in restaurants. She lived far apart from her first husband and moved with her second husband all over the world. The cast of feminist characters set before her in her writing profession was rich and varied. Her unusual life had acquainted her with every possible type of feminist nature. So she kept her feminist perspective all the time. Those acquaintances strengthened all her writing, but she had never written better than when she wrote of women in or from ancient China.

Her close attention to the survival state of Chinese women also means focusing on history, women's history, Chinese women's history and history of women's literature. Most of her writings have reflected the historical and tough-minded fate of females and tried to constitute a female's reality in the world. In an international cultural environment, there exist some generalities and particularities in the life of the Chinese women. The patience and benign attitude in Chinese ethical culture have been hidden from view for nearly a hundred years. However, in Fusang, Yan Geling has devoted a long-lost classic work by artistically activating the feminine good virtue and brought a new realization of maternal greatness.

\section{Fusang, the Historical Reconstruction of Humble Women}

\subsection{A Short History of Oppressed Women}

Fusang gives a glimpse of the Chinese women's history. Making a general survey of human history, all people will admit the indisputable fact that women have been living in an oppressed status which they have been trying to be rid from. In ancient China, prostitutes were undoubtedly the most oppressed. In a society where people advocated the concept of "Lady without talent is a matter of virtue", women's freedom of thoughts and actions was strangled and they had to live on men for existence. Once they lost men's protection, many women would usually have no other way but to live on their bodies and reduce themselves to prostitutes. But their miserable encounters seldom won social sympathy. In most cases, they would be condemned to and disdained by men at the time when they were sensually trampled by men. In the long history of China, there have been once so many famous prostitutes, including so many characters such as Su Xiaoxiao, Li Shishi, Chen Yuanyuan, Li Xiangjun, Dong Xiaowan and Diao Chan. 
All of them were unmatched beauties, and all of them were of noble virtue. However, nearly all of them had a tragic end of their life. This cruel fact has distinctly shown that women have been living under oppression.

\subsection{Fusang, a Victim of Chinese Traditional Concept of Ethics}

In Fusang, Yan Geling revealed a history of oppressed women that had been covered with dust for a long time. In this novel, through Fusang, an overseas Chinese prostitute, Yan appealed boldly for a correct evaluation of women struggling in abysm and showed deep concern over women's status, destiny and rights, and bore a conspicuous tint of feminism. Fusang was a typically oppressed woman, who not only experienced numerous sufferings but also hummed with all the virtues of ancient Chinese women. She was an esteemed goddess as well as an ignoble whore. As a girl from impecunious China, she was looked down upon by the white race and even her fellow country men. However, she touched her surrounding world greatly with her virtuous, frugal, lenient, caring, dedicated and self-motivating spirit. It is the very traditional virtue reflected by the Chinese women that often surprises gentlemen in a foreign country. Although Fusang suffered greatly from oppression, she played a superlative song of the highest virtue in misery. She was a prostitute, but she owned the great virtue of a holly virgin.

\section{Fusang's Greatness Concealed in Her Ignoble Representation}

\subsection{The Representative and Ignoble Features of Fusang}

Fusang lived in a period when the feudal society would die out and capitalist society began to sprout. At that time, the feudal thought that women were inferior to men had deeply branded in women's minds. Women's destiny should only be arranged by men. So from the day Fusang was born, she was doomed to be a weak one, not only in body but also in ideology. She could only live by attaching herself to the patriarchal society. When Fusang was only an innocent baby in her cradle, her father already married her to a stranger. Since then, her life was, without any choice, sentenced to a man whom she never met. Her slow of mind and speech was viewed as a big advantage in the eye of her husband's families, for "once she married in, they could treat her like chattel and she wouldn't say a word of reluctance." Although Fusang's husband had left home for a gold rush, she was still constrained by her husband's family. When grown up, she was made to kowtow with a cock, instead of her husband on her wedding. And she began to do the entire household since the day she arrived in the family. Fusang was always mocked by others, "Your mother-in-law has married you in for herself. Don't you know that?" Several years after the marriage, she was abducted and stepped onto a ship to the America. With great expectation, Fusang set foot on the foreign land. But she still could not rid herself of the oppression of patriarchal society. Without any economic ability and survival skills, she was sold to be a prostitute. In order to survive, she had to devote her body to any man, one after another. At the same time, her weak life turned to ignoble fate.

Fusang hated to be a prostitute, so she once tried to rail against her fate. She ran off with another girl. But she came back voluntarily the next day. All sympathetic people may congratulate her for her escape. But her unexpected return cruelly discouraged so many readers. Some may angrily think that she would degrade herself and had no real sense of rebellion at all; some may feel that she was a little imbecile. However, if they will put themselves in Fusang's place, the readers will know that without the hateful whorehouse, it was impossible for a girl like Fusang to survive in the patriarchal society. She had no alternative, since she had no money, no skill, and no social status. She even had no right to own them. The patriarchal society had deprived her of everything materially and psychologically. The only thing she possessed was her meal ticket, her body. In order to earn her basic sustenance, she had to keep selling her body to men.

\subsection{Fusang's Helpless Greatness Reflected by Her Inexplicable Smile}

In old China, a woman was often a helpless mess. As a virgin, she had to obey orders of her parents; as a bride-to-be, she had to go in accordance with the advice of her match-maker; as a married woman, she had to follow her husband and act on his volition; and as a mother, she had to listen to her son in dealing with things once her husband died. So she would have a lot of frustration with family and social life. Every "honest woman" was helpless for it, and so was Fusang.

In the novel, Fusang was commonly without assistance. Whenever it happened, she would do nothing but smile inexplicably. Her smile became the indication of her frustration. Her helplessness was repeatedly betrayed by her wordless smile. This smile did not mean that she was happy and gay. In Fusang's story, her smile was mentioned several times. In fact, she dealt with all things and people with her impressive smile. When the trader told Fusang that her mother-in-law had married her in for herself, she said nothing but smiled and kept doing her work. In front of the whoremaster, Fusang did not flirted wounded, but she did not speak anything in defense of herself, seemingly not knowing what people were arguing for. She did nothing but lowered her head and smiled heartily to herself. For Dayong's sake, she did not hesitate to be maligned as a thief. All reasonable people will laugh at Fusang for her idiotic choice. And in a sense, she was odiously silly. She was unforgivable for foolishness. However, we have no 
alternative as she did if we put ourselves in her position. She already knew at that time that Dayong was her long-seeking husband and only relative in the strange land, no matter whether he was bad or not. To Fusang, a woman raised on traditions, the loss of that man meant the loss of all hopes and spiritual support. So her decision is a helpless choice, whether others can understand it or not.

To some, Fusang's smile on a special occasion may often be inexplicable since she always smiled, even before danger. Actually, her smile often meant challenging, unyielding and subjugating. Once at an auction, Dayong, already a trader, choked an innocent baby to death in order to hide from the police, and then raised a flame up directly to Fusang. However, she didn't duck away, instead, she gave him a smile. It is a "sudden, unconscious, simpleminded smile of a lamb at slaughter." Fusang's smile always seemed to be superficially unconscious, yet in fact derived from her inner reaction. They were unquenchable smiles; they were helpless smiles; they were also courageous smiles. These smiles will not be restrained by anything. Females, like Fusang, could do nothing in face of males' cruel persecution. In many cases, their spiritual rebellion and physical resistance can prove nothing, so a queer smile may be helpful.

Chris witnessed Fusang's merciless ravage from countless whore masters when he was very young. He showed deep concern for her and planned to offer some help. One day, Chris bought Fusang for a night with ten dollars in order to rid her away from sensual torture for the time being. However, there was no appreciative and delighted expression as he had been expected to appear in her face. Instead, when she learnt this, she only smiled and faced the "young whore master" wordlessly with an unspeakable expression appearing in her face. There was everything except gratitude or thanks in it. She was at a loss as how to make the innocent boy understand that her life had been closely connected with misery. She knew that she had been combined with blood, suffering and pleasure. To Fusang, escaping out of misery meant escaping out of life. That was another aspect of Fusang's helplessness. Its theoretical basis of the helpless smile rooted in the soil of fatalism.

As a matter of fact, all people find themselves at some point helpless. But why does there always exist too much helplessness in people's life? Helpless people, how do you often solve your helpless problems? To those who live in a special condition, helplessness is a common occurrence. In Fusang's life, Chris was the second male that she loved whole-heartedly. But she couldn't marry the well-to-do young man in order not to influence his future negatively. Chris was captivated by Fusang. In his eye, she could be compared to a saintess. But he was a man of poor mental health and liked to see Fusang dressed in her bloodied and dirty red skirt, so when he saw her in a clean white dress and lying in bed in the hospital, his obsessed appreciation disappeared immediately. He even wondered if she deserved his love. In his eye, that red skirt was not only a part of her body, but the true symbol of her nature. The clean white dress erased all the oriental traces embodied by Fusang: degeneration, crime, evil, corruption and contemptibility. What he was infatuated with was the prostitute who lay in bamboo bed in the whorehouse, opening her body to the whole world.

As the novel goes, Fusang perceived Chris' psychological suggestion and she smiled to herself. She knew that, without her oriental red blouse, without her oriental living environment, she could not be Chris' dreaming lover anymore. So in order to satisfy Chris' psychological need, Fusang once again dressed herself in her red satin blouse, a symbol of sin and lewdness. In Chris eyes, the change of clothes meant the resurrection of Fusang and the primitive oriental virgin. To Fusang, it is another helplessness and greatness.

\section{Fusang's Elegy for the Spiritual Salvation}

In Yan Geling's literary works, the heroines always keep a watchful eye to the world and all the things around them with their pity and sympathy. In front of shame and disaster, they often represent amazing clemency and tolerance and return goodness for all ugliness and impudicity in human nature. Their primary maternal love and good human nature often urge them to fulfill the salvations toward people who lose their virtue and human nature. What was it that gave them the strength and courage to tolerate everything? It is maternity. This kind of maternity makes a kind of sacrificing feeling. The feeling contains a spirit of suffering willingly and selfless devotion and sacrifice. A female like Fusang is "as good as water" (an analogy in Chinese). She is the feeblest; meanwhile, she is also the strongest in the world.

\subsection{Fusang's Humanistic Salvation to Dayong}

Dayong was a complicated figure in the novel. He was a famous mob. On the one hand, he had a ruthless character, enjoying satisfaction in human trafficking and he could even kill an innocent baby without hesitation. On the other hand, he was the one who dared to say "No" to Caucasians. He fought with white human traders on the ship and organized the Chinese laborers to strike. To this man, Fusang was only a pet and a tool to release wants. But Fusang was dedicated to taking care of Dayong's daily life. She never said no to his arrangement and decision. She could not remember the name of any of the whore-masters, but remembered clearly every habit and itching of Dayong. Even after suffering gang-rape during a revolt, she also prepared soup for Dayong as usual on the next morning. 
When Fusang knew that the man who had bought and sold her was the husband she had been looking for, she may had sorrow, desperation and anger in her heart. But she kept the misery for herself and bore all the pain silently. The silent Fusang was dumb in front of Dayong. Her silent tolerance of misery changed him gradually.

More and more goodness were revealed in Dayong's human nature. He stopped selling prostitutes and stopped killing people arbitrarily. When he found that the watchman of the whorehouse stole his money and wanted to run away, he did not kill the watchman as he did in the past. He simply said, "Go away". He also stopped treating Fusang as a pet and a tool for making money. He was purified by what she did and began to respect her. He wanted to marry her off to make her live a normal life as a normal woman. For the sake of Fusang's happiness, he decided to marry her to the one whom she could recognize by name. When Fusang misnamed all the men, he decided to give her freedom. In fact, she had recognized Dayong by the silver bracelet a long time ago. But she knew that since the day she was driven to prostitution, she could not return to the normal life any more. According to Chinese traditional concepts, she had lost the right to be a wife. The wife in home was the only spiritual support for Dayong. In order to maintain the beautiful imagination and hope in Dayong's heart, she turned his capital punishment into the most glorious moment of his life with marriage. So he died with deliberation in the longing for happiness. Fusang used marriage to perform a wife's responsibility for the last time. The contradiction between female and male under the paternity and manus is defused. By that time, the contradiction was deduced to a romantic love legend. Dayong who seemed strong in fact had become the object of remorse and pity.

\subsection{Fusang's Spiritual Salvation to Chris}

To Chris, Fusang was a beautiful legend and story of the Orient. Her every smile and gesture contained myth of the magic orient. His primal desire and deep-seated impulse were lifted by her red blouse. So in a revolt in the Chinatown, he raped the Chinese beauty. But Chris was not an evildoer in nature. He began to be tormented by his conscience later and he hoped that Fusang did not know who committed this crime. However, she discovered evidence of the crime, a brass button from his coat which she kept in her hair silently during the violation.

Fusang hated Chris, but the Chinese original ethical concept had made her a tenderhearted maid. So when she saw the sad eyes and knew that Chris suffered a lot for her, her hatred melted and she forgave him by pretending she could not remember him. She did not have the heart to see him troubled in the mind all the time and responded to Chris crime with her tolerance, sympathy and care. In fact, she even transformed her hatred into love. Fusang's behavior and attitude made Chris feel ashamed of himself. So he decided to make up for his outrage and compensate Fusang for her sufferings with a marriage. Chris dated with her regardless of his father's instructions, directly betraying his family. But Fusang always held a sheltered love which was full of maternity. This kind of tender love from a mother toward her son made Chris become more infatuated.

In order to answer Chris love, she refused the marriage proposals from other men and abandoned her chance to have a normal life. But she did not choose to live with him. In face of happiness, she suppressed her love and chose self-sacrifice, since she knew that the standard of the cultural society required a woman to be of clean body and heart and to follow the prescribed norms. Maybe, Chris would really marry her, but they may not be able to keep love and marriage at an identical position all the time. Fusang was a kind of beauty which generated from crime. She could not exist in the cultural criterion and order. All the education, family and discipline of Chris could not bear such a woman like Fusang. She understood the identity and status of herself, so she suppressed her affection toward him. She cut off this entanglement with Chris by a separate marriage. She used marriage to make sacrifice and protection for Chris for the last time. Her choice preserved their love at the most beautiful moment which left Chris a sweet memory. Her cruel choice was decided for the benefit of Chris future.

Fusang lost her only love as she fulfilled a spiritual salvation toward him. Her sacrifice produced a condition of the harmony in Chris's family and made Chris safe against ridicule and discrimination. Fusang's decision shocked Chris and made her shine before him. At the same time, Fusang became his 'forever'. He was completely purified in the soul. In his later days, he spent his whole life on opposing the persecution of Chinese. He tried his best to save Fusang's fellow men with a grateful mind. He developed Fusang's salvation into a new range which transcended gender and race.

\section{Conclusion}

All in all, Fusang was a woman with bountiful vitality. As a prostitute, she might be looked down upon by conventional people, yet many traditional virtues of an oriental female embodied in her can be respected by most people. Her docile, humble, perseverant, apprehensive and self-sacrificing character will be extolled by all men. A woman like Fusang may live in whatever humiliating and humbling environment, but her humanity and maternity will always shine brightly. Therefore, an individual's greatness cannot be judged objectively by his or her earthshaking achievements, but by his or her extraordinary approach in dealing with the ordinary. This is the main melody of Fusang's virtuous song. While reading Fusang, a careful reader may find a strangely familiar gaudiness to 
it. It is not a literal gaudiness, nor a descriptive gaudiness. It is the primitive gaudiness inherent within humanity.

An outstanding literary work offers esthetic sentiment at the time when it plays a positive role in enriching both the writer and the readers' knowledge and cultivating an even-keel temperament. Just as Yan Geling informally said in an interview, "As a writer, you can't lose your artistic conscience even if you will not assume any cultural and political responsibility. You have to carry out your bound duty: aesthetic satisfaction. Your writing is successful if you have earnestly excavated aesthetic value in your narration." As a matter of fact, Yan's basic prerequisite of success in her writing is her tireless pursuit of uncommonly aesthetic value. That is the foundation upon which she establishes her creative writing. Therefore, she can continue creating her imaginative, artistic literature. Her rich and tortuous experiences of time and emotions have greatly influenced the formation of her writing style and encourage her to maintain a watchful eye on the mental world of those vivid people treading on the fringes of society. They might be of little importance in the real life, yet they performed a melody of true benevolence at the cost of emotional sufferings. Fusang, as well as many other female characters in her other novels, dragged out an ignoble existence in order to realize her illusory ambition, while never losing her authenticity at any life stage. So Fusang's story is not only a thought-provoking novel, but also a bloody history that paints a portrait of the reality of Chinese immigrants. That is a central motivation for Yan Geling to write this book. That is motivating force behind Yan Geling's literary thoughts and feelings in expressing the profound effects and experiences of women.

\section{References}

Bloom, Harold. (1997). Asian American Women Writers. Philadelphia: Chelsea House Publishers.

Chen, Sihe. (2006). On Oriental Ethics from the Humanistic Perspective - A Research of Yan Geling. Shantou: Shantou University Press.

Huang, Guiyou (2006). Asian American Literary Studies. Columbia University Press.

Wang, Chunrong. (2006). Women's Survival and Feminine Culture Study. Shenyang: Liaoning University Press.

Xiao, Wei. (2009). On Female Writing in Heterogeneous Culture Context. Chengdu: Bashu Pulishing House.

Yan, Geling. (2009). Fusang. Xian: Shaanxi Normal University Press.

Yan, Geling.(2002). Mainstream and edges. Shanghai: Shanghai Art and Literature Publishing House.

Yin,Xiao-huang. (2000). Chinese American Literature since the 1850s. University of Illinois Press. 